\title{
miR-632 promotes gastric cancer progression by accelerating angiogenesis in a TFF1-dependent manner
}

\author{
Ying Shi ${ }^{1,2^{*}}$, Xiaoxiao Huang ${ }^{3}$, Guobin Chen ${ }^{4}$, Ying Wang ${ }^{4}$, Yuansheng Liu ${ }^{3}$, Wei Xu ${ }^{5}$, Shaohui Tang ${ }^{1,2}$,
} Bayasi Guleng ${ }^{3}$, Jingjing Liu ${ }^{3^{*}}$ and Jianlin Ren ${ }^{3^{*}}$

\begin{abstract}
Background: Gastric cancer (GC) is a common malignant disease worldwide. Aberrant miRNAs expression contributes to malignant cells behaviour, and in preclinical research, miRNA targeting has shown potential for improving GC therapy. Our present study demonstrated that miR-632 promotes GC progression in a trefoil factor 1 (TFF1)-dependent manner.

Methods: We collected GC tissues and serum samples to detect miR-632 expression using real-time PCR. A dual-luciferase reporter assay was used to identify whether miR-632 directly regulates TFF1 expression. Tube formation and endothelial cell recruitment assays were performed with or without miR-632 treatment. Western blot and in situ hybridization assays were performed to detect angiogenesis and endothelial recruitment markers that are affected by miR-632.

Results: Our results showed that miR-632 is highly expressed in GC tissue and serum and negatively associated with TFF1 in GC. miR-632 improves tube formation and endothelial cell recruitment by negatively regulating TFF1 in GC cells.

Recombinant TFF1 reversed miR-632-mediated angiogenesis. TFF1 is a target gene of miR-632.

Conclusions: Our study demonstrated that miR-632 promotes GC progression by accelerating angiogenesis in a TFF1dependent manner. Targeting of miR-632 may be a potential therapeutic approach for GC patients.
\end{abstract}

Keywords: miR-632, Trefoil factor 1, Gastric cancer, Angiogenesis

\section{Background}

Gastric cancer (GC) is a common malignant disease worldwide $[1,2]$. Cancer cells invade locally and metastasize to distant sites, which leads to death [3]. A better understanding of factors that contribute to GC cell behaviour could potentially improve GC therapies. Two decades ago, microRNA (miRNA) was discovered to be a non-coding RNA and identified as a regulatory gene $[4,5]$. Currently, miRNAs are reported to regulate the development of many diseases, especially malignant tumours, by acting as either oncogenes or tumour suppressors [6-8]. miRNA dysregulation is involved in cancer progression and may provide

\footnotetext{
* Correspondence: shiying@jnu.edu.cn; jingjingliu@xmu.edu.cn; renjianl@xmu.edu.cn

${ }^{1}$ Department of Gastroenterology, The First Affiliated Hospital, Jinan University, Guangzhou 510630, People's Republic of China

${ }^{3}$ Department of Gastroenterology, Zhongshan Hospital, Xiamen University, Xiamen 361004, People's Republic of China

Full list of author information is available at the end of the article
}

targets for novel therapeutic approaches [9-12]. Several miRNA-targeted therapeutic strategies have reached clinical or preclinical development [13]. Currently, a miRNA-associated signature provides predictive power to classify and stratify EGC patients for endoscopic treatment [14]. A mimic of the tumour suppressor miR-34 has reached phase I clinical trials for cancer treatment. Anti-miR-122 therapy has reached phase II trials for hepatitis treatment [15]. Silencing of miR-632 inhibits EMT (epithelial-mesenchymal transition) and eliminates invasive ability in breast cancer cells. In addition, miR-632 is related to nasopharyngeal carcinoma, laryngeal cancer and myelodysplastic syndrome [16-18]. Tuberculosis risk may be influenced by miR-632-mediated regulation [19]. However, the relationship between miR-632 and GC therapeutics still needs to be clarified.

The trefoil factor family is a group of small-molecule polypeptides secreted by the mammalian gastrointestinal tract [20]. Trefoil factor 1 (TFF1), a member of the trefoil

(c) The Author(s). 2019 Open Access This article is distributed under the terms of the Creative Commons Attribution 4.0 International License (http://creativecommons.org/licenses/by/4.0/), which permits unrestricted use, distribution, and reproduction in any medium, provided you give appropriate credit to the original author(s) and the source, provide a link to the Creative Commons license, and indicate if changes were made. The Creative Commons Public Domain Dedication waiver (http://creativecommons.org/publicdomain/zero/1.0/) applies to the data made available in this article, unless otherwise stated. 
peptide family, has been reported to inhibit gastrointestinal tumourigenesis. TFF1 is highly expressed in the human stomach and maintains gastric epithelial structure and function [21]. However, this tissue-specific distribution is disrupted in pathological states. In metastatic GC, TFF1 is upregulated compared with its expression in primary cancer [22]. After GC resection, secreted TFF1 in serum acts as a recurrence biomarker [23]. We previously explored the effect of TFF1 in the maintenance of gastric mucosa integrity and continuity and found that TFF1 is closely associated with GC progression [24, 25]. According to a computer-based set of predictions, target sequences within the TFF gene cluster demonstrate that multiple miRNAs can potentially bind the 3 '-untranslated region and DNA coding sequence [26]. We previously showed that miR-423-5p and miR-218-5p regulate GC proliferation and invasion by targeting TFF1, respectively [27, 28].

Aberrant miRNA expression contributes to malignant cell behaviour, and in preclinical research, miRNA targeting has shown potential for improving GC therapy. Here, we demonstrate that miR-632 promotes tumour angiogenesis and endothelial recruitment in a TFF1-dependent manner.

\section{Methods}

\section{Ethics statement}

This study was approved by the Ethics Committee of The First Affiliated Hospital, Jinan University, China. Written consent was obtained from all participants.

\section{Cell culture and transfection}

AGS cell lines were purchased from ATCC (Manassas, VA, USA) and cultured in Ham's F-12 K (Kaighn's) medium (Life Technologies) supplemented with $10 \%$ foetal bovine serum (FBS, Life Technologies) and 1\% penicillin G/streptomycin (Life Technologies). BGC823, MGC803, MKN45 and EAhy926 cell lines were purchased from Cell Bank, Shanghai Institutes for Biological Sciences (Cell Bank, CAS, Shanghai, China) and cultured in RPMI 1640 medium (Life Technologies) supplemented with $10 \%$ FBS and $1 \%$ penicillin G/ streptomycin. All cell lines were incubated at $37^{\circ} \mathrm{C}$ in an atmosphere of $95 \%$ air and $5 \% \mathrm{CO}_{2}$. The cell lines were checked free of mycoplasma contamination by PCR and culture, and authenticated with STR profiling (FBI, CODIS, http://cellresource.cn).

miR-632-mimic (25 nM) and miR-632-inhibitor (50 $\mathrm{nM}$ ) were purchased from Qiagen. The cell transfection method was described previously [28].

\section{RNA expression analysis}

A miRNeasy Kit (Qiagen; cat. no. 217004) was used for total RNA extraction from human GC cells or tissues, and a miRNeasy Serum/Plasma Kit (Qiagen; cat. no. 217184) was used for miRNA extraction from GC patient serum following the manufacturer's protocol. miRNA first-strand
cDNA synthesis and real-time PCR were performed as previously described [28]. miR-632 and control primers were purchased from Qiagen. TFF1 primers were described previously [27].

\section{In situ hybridization and immunohistochemical staining} Digoxin-labelled hsa-miR-632 probe (miRCURY LNA ${ }^{\text {mu }}$ Detection probe; 250 pmol; 5'-DIG and 3'-DIG labelled; Exiqon) was used at a concentration of $1.5 \mathrm{pM}$ to detect miR-632 expression. Rabbit anti-human TFF1 polyclonal antibody (ab92377) was purchased from Abcam and diluted 1:250 in IHC Antibody Diluent (ABD-0030; Maixin Biotech, Fuzhou, China). Anti-MMP9 (MAB-0245) and anti-CD34 (MAB-0034) antibodies were purchased from Maixin Biotech, Fuzhou, China. In situ hybridization and immunohistochemical staining were performed in serial paraffin sections of human GC tissue using previously described procedures [28].

\section{Western blot analysis}

GC cells were transfected with miR-632 mimic or inhibitor or with corresponding controls for $48 \mathrm{~h}$. Then, the cells were collected and lysed for Western blot analysis. Primary antibodies against TFF1 were purchased from Santa Cruz Biotechnology, and antibodies targeting MMP9, CD34, p-NFkB, and NFkB were purchased from Cell Signalling Technology. Primary antibodies against GAPDH and anti-rabbit/mouse secondary antibodies were purchased from Proteintech.

\section{Dual-luciferase reporter assay}

AGS cells were seeded in 24-well plates at a density of $6 \times$ $10^{4}$ cells per well immediately prior to transfection. pmirGLO dual-luciferase miRNA target expression vector was purchased from Promega (cat. E1330). The full-length or a mutated 3'UTR region of TFF1 was inserted into a luciferase reporter vector. AGS cells were co-transfected with miR-632-mimic along with the vectors. After $48 \mathrm{~h}$, the cells were assessed for both firefly and Renilla luciferase activity using a dual-luciferase reporter assay system (Promega; E1910).

\section{Enzyme-linked immunosorbent assay (ELISA)}

After $24 \mathrm{~h}$ of miR-632 mimic or inhibitor treatment, cell supernatants were collected and examined using a TFF1 ELISA kit (USCN Life Science, Houston, TX, USA) following the manufacturer's protocol. The absorbance at $450 \mathrm{~nm}$ was measured using a microplate reader.

\section{Endothelial recruitment experiment}

EAHY926 cells were grown to $100 \%$ confluency in $60-\mathrm{mm}$ dishes. Three coverslips seeded with GC cells transfected with hsa-miR-632 mimic, hsa-miR-632 inhibitor or corresponding controls were transferred onto the EAHY926 monolayer and a scratch was made across the EAHY926 
monolayer using a $200-\mu \mathrm{l}$ pipet tip. At least three images were collected along each scratch and analysed for the area covered by EAHY926 cells.

\section{Blood tube formation assays}

Gastric cells were treated with hsa-miR-632-mimic, hsa-miR-632-inhibitor or corresponding controls and incubated at $37^{\circ} \mathrm{C}$ for $24 \mathrm{~h}$. The supernatant was collected and added to EAHY926 cells. A total of $100 \mu \mathrm{l}$ Matrigel (BD Bioscience) was added to a 96-well plate and allowed to polymerize. Then, $3 \times 10^{4}$ EAHY926 cells in serum-free medium were added to each Matrigel-coated well. Cells were incubated for $6 \mathrm{~h}$ at $37^{\circ} \mathrm{C}$ and then imaged via microscopy. Each group was evaluated in triplicate.

\section{Cell migration and wound healing assays}

Cell migration was analysed using Transwell and wound healing assays. The Transwell assay was performed using 24-well Transwell plates (Costar, USA) polycarbonate filters containing $8-\mu \mathrm{m}$-poros. Briefly, $200 \mu \mathrm{l}$ of cell suspension containing $1 \times 10^{5}$ cells in the absence of FBS was added into each upper Transwell chamber, and $500 \mu \mathrm{l}$ of medium containing 10\% FBS was added to the lower chamber. The cells were incubated for $20 \mathrm{~h}$ and then fixed in $4 \%$ paraformaldehyde for $10 \mathrm{~min}$. Cells were stained with $1 \%$ crystal violet for 30 min and counted.

Wound healing assays were performed in 6-well plates. Cells were cultured in 6-well plates at a density of $5 \times$ $10^{6}$ cells per well for $24 \mathrm{~h}$, and then, a scratch was made across the cell monolayer with a $200-\mu l$ pipet tip. At least three images were collected along each scratch and analysed for the area covered by cells.

\section{Statistical analysis}

Statistical analysis was performed using SPSS 21.0 software (SPSS Inc., Chicago, IL, USA). Student's t-test (means \pm standard deviation) and chi-square test were used for data analysis according to different data types. All of the values are expressed as the mean $\pm S D$ of at least three independent experiments performed in triplicate, and $P<0.05$ was considered to be statistically significant. Graphs were plotted using GraphPad Prism 5.0 software (GraphPad Software Inc., La Jolla, CA, USA).

\section{Results}

\section{miR-632 is highly expressed in GC tissue and serum}

We measured the expression of miR-632 in both GC tissues and serum. We found that the expression of miR-632 was upregulated in GC tissues (Fig. 1a, left panel, $n=35$, $P<0.05$ ) and in serum of GC patients (Fig. 1a, middle panel, $n=25, P<0.01)$ compared with the corresponding controls. We also analysed the expression of miR-632 in different cell lines. Figure 1c shows that the expression of
miR-632 was upregulated in GC cells compared with normal gastric epithelial cells.

\section{miR-632 improves tube formation and endothelial cell recruitment in GC cells}

We transfected AGS and BGC823 cells with chemically synthesized miR-632-mimic oligonucleotides $(25 \mathrm{nM})$ or a corresponding control (Additional file 1: Figure S1A, $P<0.01$ ) and transfected MGC803 and MKN45 cells with miR-632-inhibitor oligonucleotides $(50 \mathrm{nM})$ or a corresponding control (Additional file 1: Figure S1B, $P<0.01$ ). After 24 $\mathrm{h}$, the supernatants were collected and used to incubate EAhy926 endothelial cells. Then, angiogenesis tube formation assays were performed (Fig. 1b). Figure 1c shows that miR-632-mimic increased angiogenesis tube formation in AGS cells and miR-632-inhibitor suppressed angiogenesis tube formation in MKN45 cells compared with the corresponding controls (Fig. 1c, $P<0.01$ ).

We generated a GC cell co-culture system to perform endothelial cell recruitment assays. GC cells were treated with miR-632-mimic or inhibitor or their corresponding controls in microplates to recruit endothelial EAhy926 cells placed in the chambers (Fig. 1d). Figure 1e shows that miR-632-mimic increased endothelial cell recruitment in AGS and BGC cells (upper panels) and miR-632-inhibitor suppressed endothelial cell recruitment in MGC803 and MKN45 cells (lower panels) compared with the corresponding controls $(P<0.05)$. GC cells were transfected with miR-632-mimic or inhibitor on microslides to recruit EAhy926 cells (Fig. 1f). Figure 1g shows that miR-632-mimic accelerated healing of a cell scratch wound compared with the control (left panels), while miR-632-inhibitor decelerated scratch wound healing compared with the control in MKN45 cells (right panels).

\section{miR-632 expression is negatively associated with TFF1 in GC}

We collected tumour samples from 35 human GC patients and measured miR-632 expression in human GC tissues. miR-632 expression was significantly up-regulated in GC lesions compared with adjacent non-cancerous tissues (Fig. 2a, left panel, $n=35, P<0.05$ ), and was negatively related to low expression of TFF1 (Fig. 2b, left panel, $n=35, P<0.01)$. We also found that miR-632 was highly expressed in GC serum compared with healthy serum (Fig. 2a, right panel, $n=25, P<0.05$ ), and was negatively related to low concentration of TFF1 (Fig. 2b, right panel, $n=25, P<0.05)$. Additional samples were collected, and the expression of miR-632 was measured by performing an in situ hybridization assay in 42 pairs of GC and adjacent non-cancerous tissues (Fig. 2c). The positive expression rate of miR-632 in GC was $71.43 \%$, significantly higher than that in adjacent non-cancerous mucosa (26.19\%) (Table 1, $P<0.00$ ). The clinical characteristics 


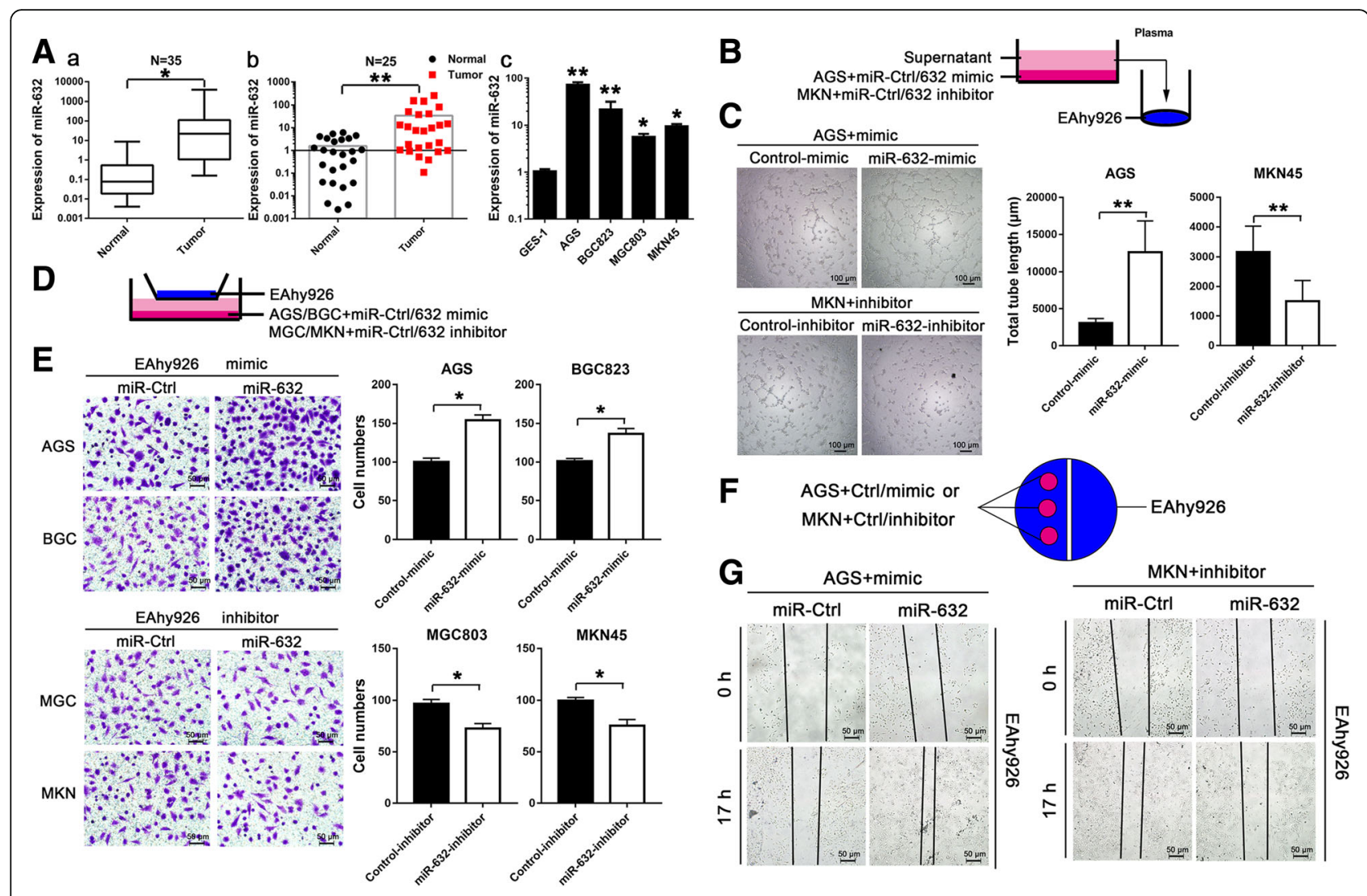

Fig. 1 miR-632 is highly expressed in GC and improved GC cell angio-tube formation and endothelial cell recruitment. a The expression of miR632 in GC tissues $(a, n=35)$ and serum ( $b, n=25)$ from both the normal population and GC patients. (c) The expression of miR-632 was significantly higher in GC cells. $\mathbf{b}$ Schematic diagram showing the miR-632-mediated tube formation assay in GC cells. c Tube formation was accelerated by miR-632-mimic in AGS cells (upper left panels). miR-632-inhibitor decreased tube formation compared with the control in MKN45 cells (lower left panels). The histograms present the total tube length (mean \pm SD) from three random fields at high magnification (right panels). d Schematic diagram showing the miR-632-mediated co-culture system using for endothelial cell Transwell assays in GC cells. e miR-632 mimic increased endothelial cell recruitment in AGS and BGC823 cells (upper left panels). The histograms present the cell numbers (mean \pm SD) from three random fields at high magnification (upper right panels). miR-632-inhibitor suppressed endothelial cell recruitment in MGC803 and MKN45 cells (lower left panels). The histograms present the cell numbers (mean \pm SD) from three random fields at high magnification (lower right panels). f Schematic diagram showing miR-632-mediated endothelial cell recruitment in wound healing assay of GC cells. $\mathbf{g}$ Wound healing was accelerated by miR-632-mimic in AGS cells (left panels). miR-632-inhibitor decelerated healing after scratching compared with the control in MKN45 cells (right panels). The experiments were performed at least three times independently. ${ }^{*} P<0.05 ;{ }^{* *} P<0.01$

related to miR-632 expression are analysed in Table 2. We also detected the expression of TFF1 and the angiogenesisrelated biomarkers MMP9 and CD34 in an immunohistochemistry staining assay (Fig. 2c). We found that TFF1 exhibited lower expression while MMP9 and CD34 showed higher expression in tumour tissues compared than in adjacent non-cancerous tissues. Thus, miR-632 expression is negatively associated with TFF1 expression in GC cells.

\section{miR-632 negatively regulates TFF1 in GC cells}

We transfected AGS and BGC823 cells with $25 \mathrm{nM}$ miR-632-mimic (Fig. 3a, $P<0.01$ ) and found that miR-632 reduced TFF 1 expression by at least $50 \%$ compared with the negative control (Fig. 3c, left panel, $P<0.01$ ). Next, we detected the concentration of TFF1 secreted by GC cells and found that miR-632-mimic decreased TFF1 secretion in AGS and BGC823 cells (Fig. 3c, right panel, $P<0.05$ ). In addition, we treated MGC803 and MKN45 cells with $50 \mathrm{nM}$ miR-632-inhibitor (Fig. 3b, $P<0.01$ ) and found that TFF1 expression was 1.75-fold higher than in the negative control cells (Fig. 3d, left panel, $P<0.01$ ). In addition, miR-632-inhibitor increased TFF1 secretion in MGC803 and MKN45 cells (Fig. 3d, right panel, $P<0.05$ ). Western blotting was performed (Fig. 3e) to verify the expression of related biomarkers in GC cells. We found that miR-632-mimic reduced the expression of TFF1 at the protein level in AGS cells compared with the corresponding control cells (Fig. 3e, left panels). However, NFkB phosphorylation showed no significant changes. In addition, we measured angiogenesis-related biomarkers and found that miR-632-mimic upregulated MMP9 and CD34 expression in tumour tissues (Fig. 3e, left panels). Moreover, miR-632-inhibitor increased 


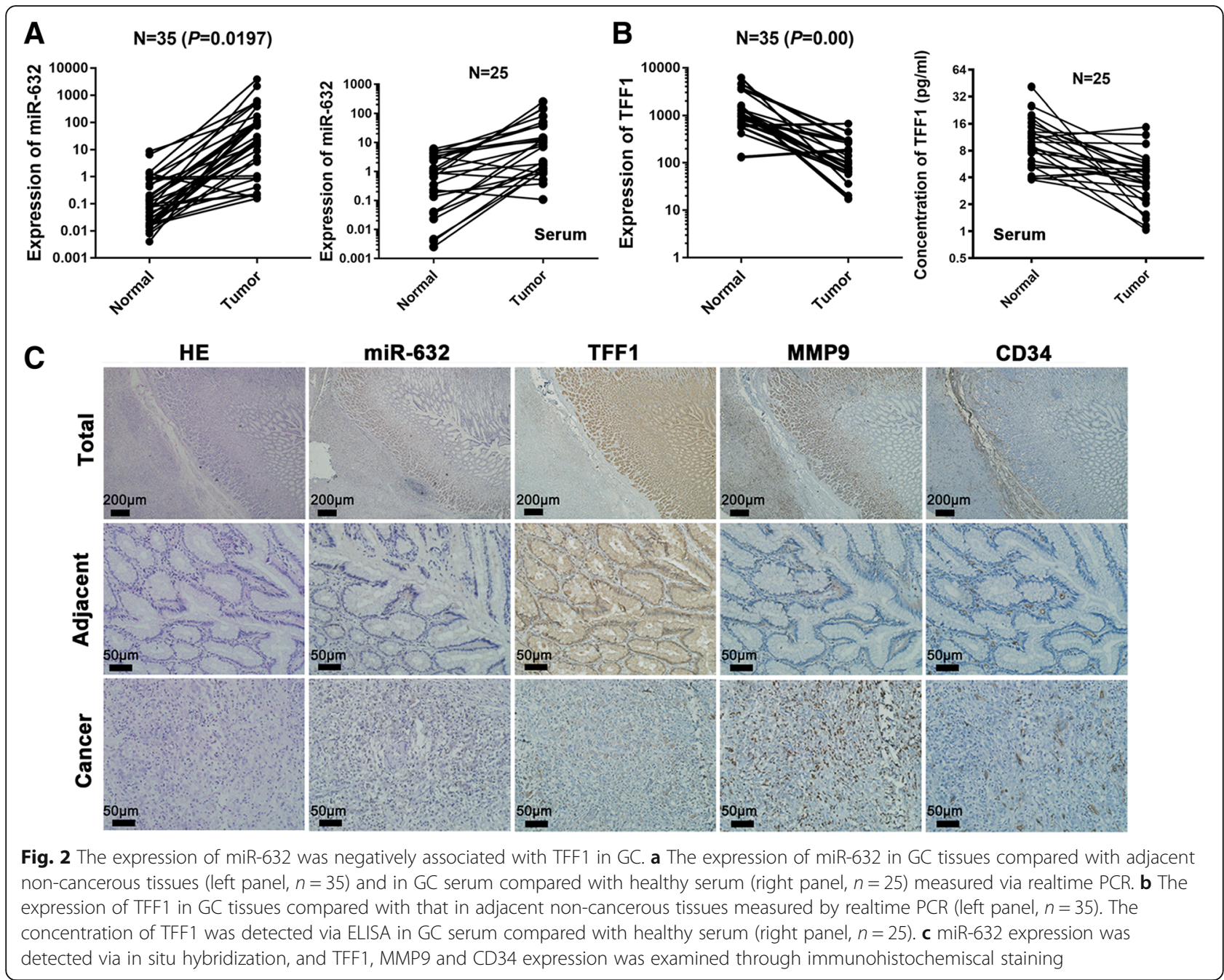

the expression of TFF1 in MKN45 cells and downregulated the expression of MMP9 and CD34 (Fig. 3e, right panels).

\section{TFF1 reverses angiogenesis mediated by miR-632 in GC cells}

Recombinant TFF1 protein $(1 \mu \mathrm{g} / \mathrm{mL})$ was used to rescue the TFF1 downregulation mediated by miR-632 in AGS and BGC823 cells (Fig. 4a, $P<0.01$ ). After recombinant TFF1 treatment, the MMP9 (Fig. 4B-a, $P<0.01$ ) and CD34 (Fig. 4B-b, $P<0.01$ ) upregulation mediated by miR-632 was significantly decreased. To confirm the effect of TFF1 on

Table 1 miR-632 expression in 42 pairs of GC tissues. The positive expression rate of miR-632 in 42 GC tissues pairs with normal gastric mucosa $(P=0.00)$

\begin{tabular}{lcccc}
\hline Group & miR-632 & & $\begin{array}{c}\text { Positive } \\
\text { rate (\%) }\end{array}$ & $\begin{array}{l}P \\
\text { value }\end{array}$ \\
\cline { 2 - 3 } & Positive & Negative & & \\
\hline Normal gastric mucosa & 11 & 31 & 26.19 & 0.000 \\
Gastric cancer & 30 & 12 & 71.43 & \\
\hline
\end{tabular}

angiogenesis mediated by miR-632, angio-tube formation (Fig. 4c) and endothelial cells recruitment (Fig. 4e) assays were performed after recombinant TFF1 treatment in AGS and BGC823 cells. Recombinant TFF1 reversed the tube formation increased by miR-632-mimic in AGS cells (Fig. $4 \mathrm{~d}, P<0.01$ ), and suppressed the endothelial cell recruitment accelerated by miR-632-mimic in AGS and BCG823 cells (Fig. 4e and $f, P<0.05$ ). Thus, miR-632 improves angiogenesis in a TFF1-dependent manner in GC cells.

\section{TFF1 is a miR-632 target gene}

We generated dual-luciferase reporter plasmids containing the full-length 3'UTR of TFF1 (pmirGLO-TFF1) or mutated potential binding sites (pmirGLO-Mut) to confirm whether miR-632 regulated TFF1 directly (Fig. 4G-a). Compared with the control, the relative luciferase activity of the pmirGLO-TFF1 reporter was markedly suppressed, with $83 \%$ expression after treatment with $10 \mathrm{nM}$ mimic and $51 \%$ expression after treatment with $25 \mathrm{nM}$ mimic (Fig. 4G-a, right panel, $P<0.05$ ). However, the activity of the reporter 
Table 2 Clinical characteristics related to miR-632

\begin{tabular}{lcccc}
\hline Characteristics & miR-632 & & $\begin{array}{c}\text { Positive } \\
\text { rate (\%) }\end{array}$ & $\begin{array}{c}P \\
\text { value }\end{array}$ \\
\cline { 2 - 3 } Gositive & Negative & & \\
Male & 22 & 5 & 81.48 & 0.114 \\
Female & 8 & 7 & 53.33 & \\
Age (yr) & & & & \\
60 yr. or younger & 13 & 6 & 68.42 & 0.695 \\
Over 60 yr & 17 & 6 & 73.91 & \\
Differentiation & & & & \\
Moderate & 21 & 8 & 72.41 & 1.000 \\
Poor & 9 & 4 & 69.23 & \\
Stage & & & & \\
I+ II & 27 & 7 & 79.41 & 0.054 \\
III+ IV & 3 & 5 & 37.50 & \\
Lymph nodes involvement & 3 & 3 & & \\
Yes & 27 & 9 & 75.00 & \\
No & & & & \\
\hline
\end{tabular}

containing a mutated site exhibited no significant alterations in cells transfected with miR-632-mimic (Fig. 4G-b). Therefore, we concluded that TFF1 is a target gene of miR-632 and that miRNA-632 negatively regulates TFF1 expression by binding to its 3'UTR.

Thus, we conclude that miR-632 promotes GC progression by accelerating angiogenesis in a TFF1-dependent manner.

\section{Discussion}

In our current study, we demonstrated that miR-632 promotes GC progression by accelerating angiogenesis in a TFF1-dependent manner. Our results showed that miR-632 is highly expressed in GC tissue and serum and negatively associated with TFF1 in GC. Here, we detected miR-632 in serum to provide an experimental basis for future non-invasive rapid diagnosis of GC using peripheral blood samples. miR-632 improves tube formation and endothelial cell recruitment by negatively regulating TFF1 in GC cells. Recombinant TFF1 reversed angiogenesis mediated by miR-632. TFF1 is a target gene of miR-632.

As important regulators of gene expression, miRNAs have not only been implicated in various signalling pathways but also in embryonic development, tissue homeostasis, stem cell transition, anticancer therapy, and other biological processes [29-31]. A miRNA-associated

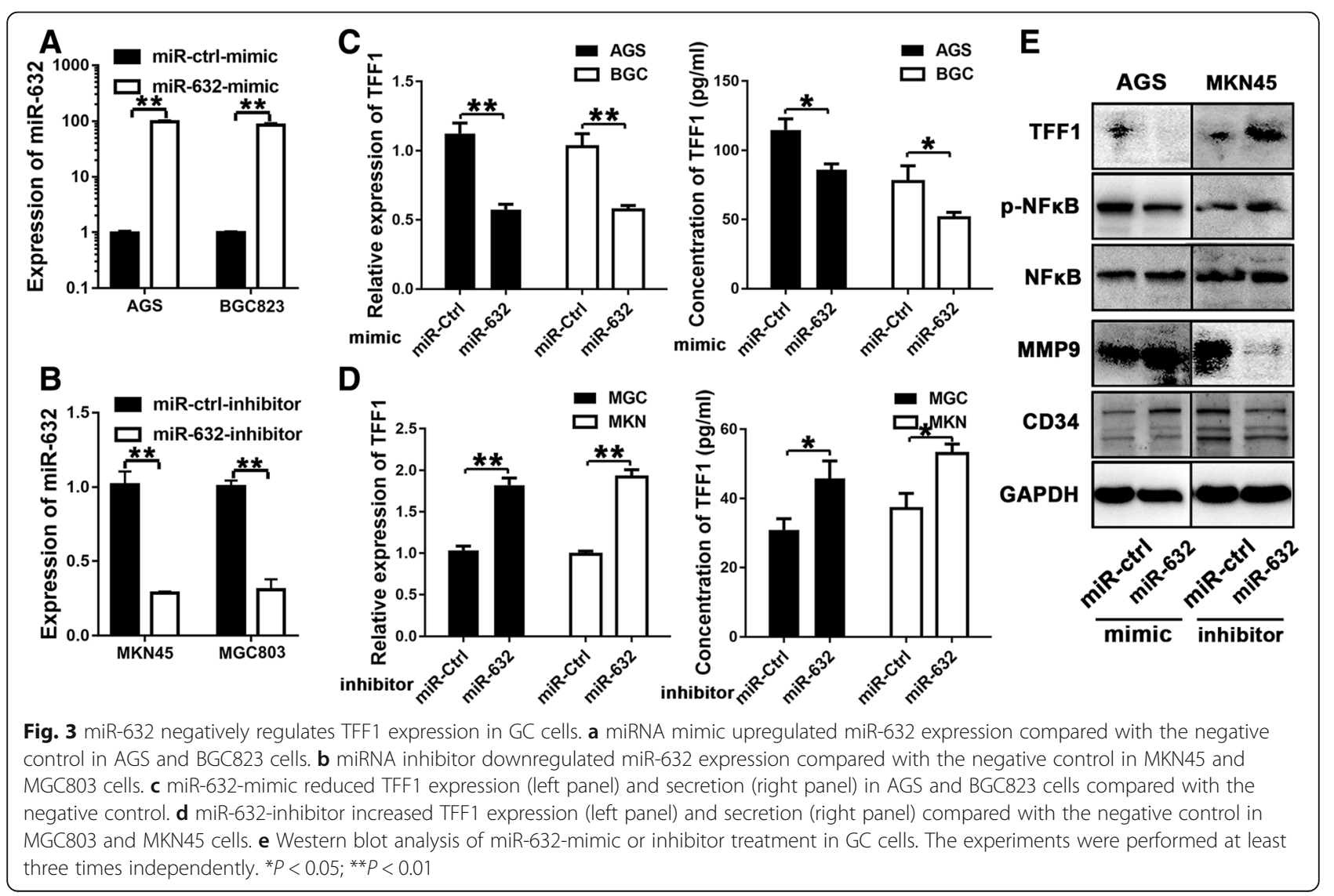




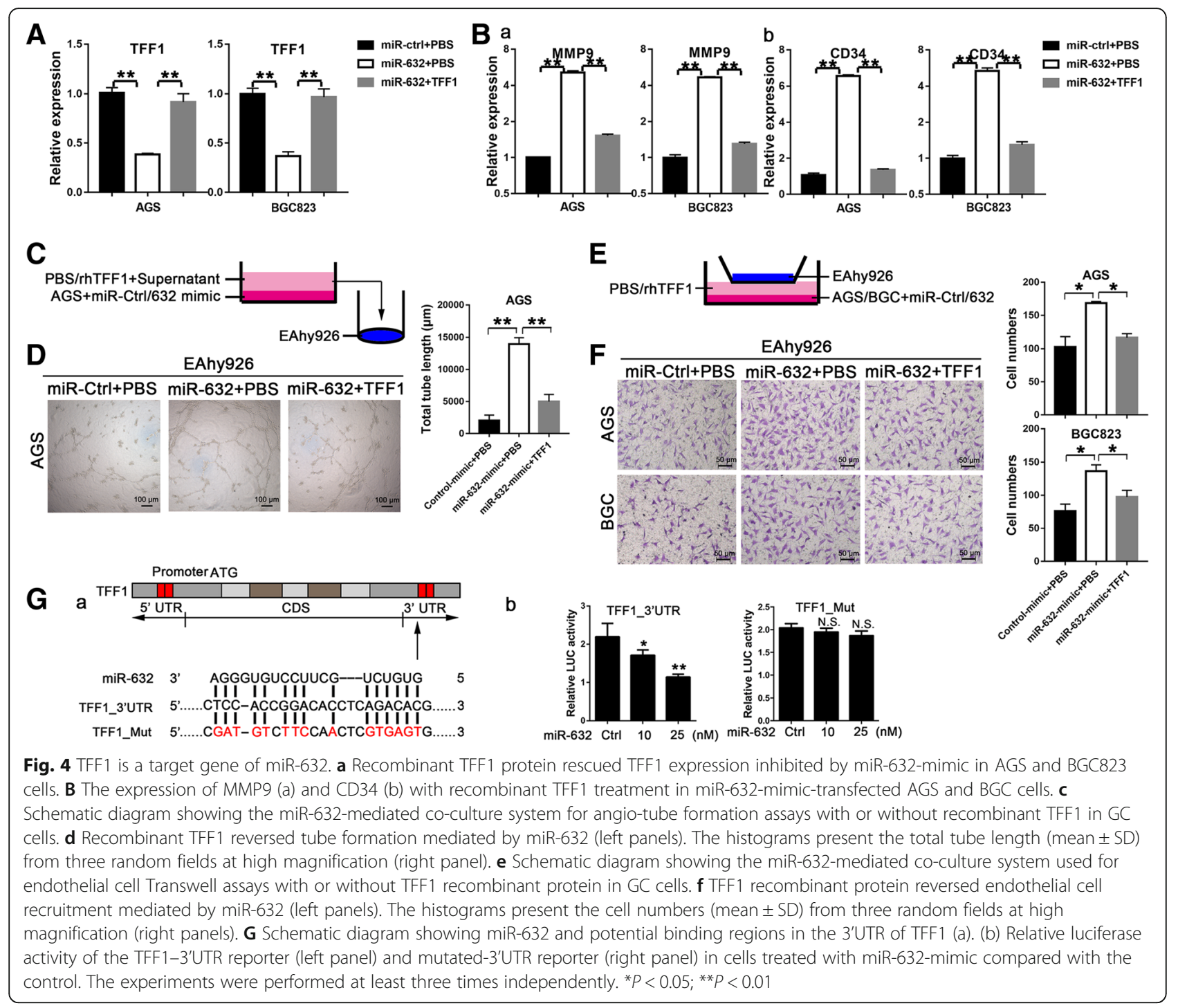

diagnosis provides predictive power to inform early GC patients and has the potential to be applied in endoscopic treatment [14]. We previously found that miR-218-5p and miR-423-5p regulate GC proliferation and invasion, respectively $[27,28]$. miR-218-5p regulates GC cell the proliferation by targeting TFF1 in an Erk1/2-dependent manner. miR-423-5p regulates cell proliferation and invasion by targeting TFF1 in GC cells. We previously suggested that TFF1 improves gastric mucosal protection and epithelial integrity [25]. Trefoil peptides are also used to protect against mucosal injury via oral administration or other approaches [32,33]. Additionally, increased TFF1 expression in para-carcinoma tissue suggests that TFF1 is associated with tumour suppression and differentiation. TFF1 is involved in inhibition of tumour invasion and migration, and it may be used as a target to enhance the chemotherapy sensitivity by regulating apoptosis resistance [34]. In addition, miRNAs can regulate TFF1 expression and secretion. In our present study, we found that miR-632 may inhibit TFF1 expression and secretion in GC cells.

\section{Conclusions}

Therefore, our research demonstrated that miR-632 is upregulated in GC tissue and serum and negatively associated with TFF1. miR-632 improves tube formation and endothelial cell recruitment by negatively regulating TFF1 in GC cells. We conclude that miR-632 promotes GC progression by accelerating angiogenesis in a TFF1-dependent manner.

\section{Additional file}

Additional file 1: Figure S1. Human GC cells were transfected with miR-632-mimic or inhibitor. (A) miRNA mimic upregulated miR-632 expression compared with the negative control in AGS and BGC823 cells. 
(B) miRNA inhibitor downregulated miR-632 expression compared with the negative control in MKN45 and MGC803 cells. The experiments were performed at least three times independently. ${ }^{* *} P<0.01$. (DOCX $233 \mathrm{~kb}$ )

\section{Abbreviations}

3'-UTR: 3'-untranslated region; GC: gastric cancer; miRNA: miR - microRNA MMP: matrix metalloprotein; TFF1: trefoil factor 1

\section{Acknowledgements}

We appreciate our colleagues Yesen Li and Zhide Guo (State Key Laboratory of Molecular Vaccinology and Molecular Diagnostics, Xiamen University, P. R. China) for their participation in the molecular and cell imaging in this work.

\section{Funding}

This study was supported by the National Natural Science Foundation of China (81370591 and 81370505); Ministry of Health Foundation for State Key Clinical Department, 863 and 973 programmes (2015CB553800) in China; Natural Science Foundation of Guangdong Province (2018A0303130302); Medical Science and Technology Foundation of Guangdong Province (A2018011); Research Foundation for Talented Scholars of Jinan University, China (89018021); and Science Foundation for The Excellent Youth Scholars of Jinan University, China (21618302); Xiamen Union Research Project of Major Disease (3502z20149031). The funding body had no role in the design of the study; data collection, analysis, and interpretation; or writing the manuscript.

\section{Availability of data and materials}

All data generated or analysed during this study are included in this published article and its supplementary information files.

\section{Authors' contributions}

$J L R, J J L$ and YS designed the experiments; YS, GBC and XXH performed cell and animal experiments and conducted statistical analysis; YW, YSL and XW performed molecular biology experiments; GB and SHT provided technical guidance. YS and JJL wrote the paper. All authors read and approved the manuscript.

\section{Ethics approval and consent to participate}

All samples were obtained with the written informed consent of patients. All cell lines were obtained by ethics approval. The Ethics Committee of The First Affiliated Hospital, Jinan University approved this study.

\section{Consent for publication}

Not applicable.

\section{Competing interests}

The authors declare that they have no competing interests.

\section{Publisher's Note}

Springer Nature remains neutral with regard to jurisdictional claims in published maps and institutional affiliations.

\section{Author details}

${ }^{1}$ Department of Gastroenterology, The First Affiliated Hospital, Jinan University, Guangzhou 510630, People's Republic of China. ${ }^{2}$ The First Clinical Medical College, Jinan University, Guangzhou 510630, People's Republic of China. ${ }^{3}$ Department of Gastroenterology, Zhongshan Hospital, Xiamen University, Xiamen 361004, People's Republic of China. ${ }^{4}$ Xiamen branch, Zhongshan hospital, Fudan University, Xiamen 361015, People's Republic of China. ${ }^{5}$ Department of Gastroenterology, The Affiliated Hospital of Guizhou Medical University, Guiyang 550004, People's Republic of China.

Received: 5 August 2018 Accepted: 26 December 2018

Published online: 07 January 2019

\section{References}

1. Siegel RL, Miller KD, Jemal A. Cancer statistics, 2018. CA Cancer J Clin. 2018; 68(1):7-30.

2. Siegel RL, Miller KD, Jemal A. Cancer statistics, 2017. CA Cancer J Clin. 2017: 67(1):7-30.
3. Hanahan D, Weinberg RA. Hallmarks of cancer: the next generation. Cell. 2011;144(5):646-74.

4. Lee RC, Feinbaum RL, Ambros V. The C. elegans heterochronic gene lin-4 encodes small RNAs with antisense complementarity to lin-14. Cell. 1993; 75(5):843-54

5. Reinhart BJ, Slack FJ, Basson M, Pasquinelli AE, Bettinger JC, Rougvie AE, Horvitz HR, Ruvkun G. The 21-nucleotide let-7 RNA regulates developmental timing in Caenorhabditis elegans. Nature. 2000;403(6772):901-6.

6. Mitchell KA, Zingone A, Toulabi L, Boeckelman J, Ryan BM. Comparative transcriptome profiling reveals coding and noncoding RNA differences in NSCLC from African Americans and European Americans. Clin Cancer Res. 2017;23(23):7412-25

7. Kim J, Yao F, Xiao Z, Sun Y, Ma L. MicroRNAs and metastasis: small RNAs play big roles. Cancer Metastasis Rev. 2017;37(1):5-15.

8. Mima K, Nishihara R, Nowak JA, Kim SA, Song M, Inamura K, Sukawa Y, Masuda A, Yang J, Dou R, et al. MicroRNA MIR21 and T cells in colorectal Cancer. Cancer Immunol Res. 2016:4(1):33-40.

9. Yang F, Ning Z, Ma L, Liu W, Shao C, Shu Y, Shen H. Exosomal miRNAs and miRNA dysregulation in cancer-associated fibroblasts. Mol Cancer. 2017;16(1):148.

10. Lan J, Huang Z, Shao J, Huang C. Redox regulation of microRNAs in cancer. Cancer Lett. 2018:418:250-9.

11. Utaijaratrasmi $P$, Vaeteewoottacharn $K$, Tsunematsu $T$, Jamjantra $P$, Wongkham S, Pairojkul C, Khuntikeo N, Ishimaru N, Sirivatanauksorn Y, Pongpaibul A, et al. The microRNA-15a-PAl-2 axis in cholangiocarcinoma-associated fibroblasts promotes migration of cancer cells. Mol Cancer. 2018;17(1):10.

12. Rupaimoole R, Calin GA, Lopez-Berestein G, Sood AK. miRNA deregulation in Cancer cells and the tumor microenvironment. Cancer Discov. 2016;6(3):235-46.

13. Rupaimoole R, Slack FJ. MicroRNA therapeutics: towards a new era for the management of cancer and other diseases. Nat Rev Drug Discov. 2017;16(3):203-22

14. Yu L, Wu D, Gao H, Balic J, Tsykin A, Han TS, Liu YD, Kennedy CL, Li JK, Mao $J Q$, et al. Clinical utility of a STAT3-regulated microRNA-200 family signature with prognostic potential in early gastric cancer. Clin Cancer Res. 2018.

15. Png KJ, Halberg N, Yoshida M, Tavazoie SF. A microRNA regulon that mediates endothelial recruitment and metastasis by cancer cells. Nature. 2011;481(7380):190-4.

16. Liu M, Zhu K, Qian X, Li W. Identification of miRNA/mRNA-negative regulation pairs in nasopharyngeal carcinoma. Med Sci Monit. 2016;22:2215-34.

17. Lu E, Su J, Zhou Y, Zhang C, Wang Y. CCL20/CCR6 promotes cell proliferation and metastasis in laryngeal cancer by activating p38 pathway Biomed Pharmacother. 2017:85:486-92.

18. Erdogan B, Facey C, Qualtieri J, Tedesco J, Rinker E, Isett RB, Tobias J, Baldwin DA, Thompson JE, Carroll M, et al. Diagnostic microRNAs in myelodysplastic syndrome. Exp Hematol. 2011;39(9):915-26 e912.

19. Song X, Li S, QuCuo M, Zhou M, Zhou Y, Hu X, Zhou J, Lu X, Wang J, Hua $W$, et al. Association between SNPs in microRNA-machinery genes and tuberculosis susceptibility in Chinese Tibetan population. Mol Biol Rep. 2013 40(10):6027-33.

20. Rio MC, Chenard MP, Wolf C, Marcellin L, Tomasetto C, Lathe R, Bellocq JP, Chambon P. Induction of pS2 and hSP genes as markers of mucosal ulceration of the digestive tract. Gastroenterology. 1991;100(2):375-9.

21. Taupin D, Podolsky DK. Trefoil factors: initiators of mucosal healing. Nat Rev Mol Cell Biol. 2003;4(9):721-32.

22. Kim JH, Kim MA, Lee HS, Kim WH. Comparative analysis of protein expressions in primary and metastatic gastric carcinomas. Hum Pathol. 2009;40(3):314-22.

23. Aikou S, Ohmoto Y, Gunji T, Matsuhashi N, Ohtsu H, Miura H, Kubota K, Yamagata $Y$, Seto $Y$, Nakajima A, et al. Tests for serum levels of trefoil factor family proteins can improve gastric cancer screening. Gastroenterology. 2011;141(3):837-845 e831-837.

24. Sands BE, Podolsky DK. The trefoil peptide family. Annu Rev Physiol. 1996;58:253-73.

25. Ren JL, Luo JY, Lu YP, Wang L, Shi HX. Relationship between trefoil factor 1 expression and gastric mucosa injuries and gastric cancer. World J Gastroenterol. 2005:11(17):2674-7.

26. Shah AA, Blin N. Target sequences for microRNAs within the Tff gene cluster. BioChip Journal. 2010:4(4):279-84.

27. Liu J, Wang $X$, Yang $X$, Liu Y, Shi Y, Ren J, Guleng B. miRNA423-5p regulates cell proliferation and invasion by targeting trefoil factor 1 in gastric cancer cells. Cancer Lett. 2014;347(1):98-104.

28. Shi Y, Chen GB, Huang QW, Chen X, Liu JJ, Xu W, Huang XX, Liu YP, Xiao $C X, W u$ DC, et al. miR218-5p regulates the proliferation of gastric cancer cells by targeting TFF1 in an Erk1/2-dependent manner. Biochim Biophys Acta. 2015;1852(5):970-9. 
29. Treiber T, Treiber N, Plessmann U, Harlander S, Daiss JL, Eichner N, Lehmann G, Schall K, Urlaub H, Meister G. A compendium of RNA-binding proteins that regulate MicroRNA biogenesis. Mol Cell. 2017;66(2):270-284 e213.

30. Du P, Pirouz M, Choi J, Huebner AJ, Clement K, Meissner A, Hochedlinger K, Gregory RI. An intermediate pluripotent state controlled by MicroRNAs is required for the naive-to-primed stem cell transition. Cell Stem Cell. 2018; 22(6):851-64 e855.

31. Hydbring P, Wang Y, Fassl A, Li X, Matia V, Otto T, Choi YJ, Sweeney KE, Suski JM, Yin H, et al. Cell-cycle-targeting MicroRNAs as therapeutic tools against refractory cancers. Cancer Cell. 2017;31(4):576-90 e578.

32. BABYATSKY MW, DEBEAUMONT M, THIM L, PODOLSKY DK. Oral trefoil peptides protect against ethanol- and indomethacin-induced gastric injury in rats. Gastroenterology. 1996;1 10:489-97.

33. Vandenbroucke K, Hans W, Van Huysse J, Neirynck S, Demetter P, Remaut E, Rottiers $\mathrm{P}$, Steidler $\mathrm{L}$. Active delivery of trefoil factors by genetically modified Lactococcus lactis prevents and heals acute colitis in mice. Gastroenterology. 2004;127(2):502-13.

34. Pelden $\mathrm{S}$, Insawang T, Thuwajit C, Thuwajit P. The trefoil factor 1 (TFF1) protein involved in doxorubicininduced apoptosis resistance is upregulated by estrogen in breast cancer cells. Oncol Rep. 2013;30(3):1518-26.

Ready to submit your research? Choose BMC and benefit from:

- fast, convenient online submission

- thorough peer review by experienced researchers in your field

- rapid publication on acceptance

- support for research data, including large and complex data types

- gold Open Access which fosters wider collaboration and increased citations

- maximum visibility for your research: over $100 \mathrm{M}$ website views per year

At $\mathrm{BMC}$, research is always in progress.

Learn more biomedcentral.com/submissions 